\title{
Teatro y metateatro en la dramaturgia de Luis Riaza
}

PEDRo RuIZ PÉREZ

Universidad de Córdoba

Inevitablemente, el creador acosa siempre los mismos fantasmas a lo largo de toda su producción. El análisis de la poética teatral del autor de Retrato de Dama con perrito revela sin ninguna dificultad una preocupación fundamental como eje de todo su teatro: la de poner al descubierto el funcionamiento de los diferentes mecanismos que contribuyen a desrealizar la existencia, es decir, a despojarla de todo valor de realidad a través de un proceso de enajenación. Estos mecanismos encuentran para Riaza su paradigma más cercano en la forma teatral, en este procedimiento ejemplar de sustitución de la realidad por una ficción. En el teatro la ficción se superpone a la realidad, la anula y la despoja de sus características, adoptándolas para su propio disfraz. En todas y cada una de las obras de Riaza toma cuerpo la conciencia que el autor tiene del teatro como mecanismo de alienación, que funciona sirviéndose de procedimientos de fingimiento y simulación. Esta idea recorre toda su producción teatral, hasta el punto de constituir una de las características más definitorias de su dramaturgia, como el propio autor ha señalado:

Siempre se escribe la misma obra. Los oscuros gusanos de cada dramaturgia siempre son los mismos y siempre procura uno librarse de ellos con los mismos exorcismos. Los de mi teatro particular puede que consistan en un ataque sañudo, terco y más o menos solapado contra todo teatro ${ }^{1}$.

1 Riaza, Luis, «Pequeño paseo ante el retrato de una dama y sus perritos resplandecientes», prólogo a Retrato de Dama con perrito, Madrid, Fundamentos, 1976, p. 15. 
Sobre este tema base, Riaza ha edificado los diversos subtemas o variaciones temáticas que constituyen las realizaciones concretas de su dramaturgia. Empleando términos tomados de la lingüística generativa chomskiana y salvando las naturales distancias que separan los respectivos campos de aplicación, podríamos afirmar que la dramaturgia de Riaza está conformada por una estructura profunda constante que presenta diferentes realizaciones o estructuras de superficie. Hemos de matizar, no obstante, que cuando nos referimos a «estructuras superficiales» en este contexto no pretendemos designar los diversos textos o formas determinadas de las piezas teatrales riacescas, sino los temas concretos que subyacen y ordenan cada una de estas obras ${ }^{2}$. La obsesión por el teatro como mecanismo de sustitución de la realidad, el tema genérico de la obra dramática de Riaza, no se ha mantenido como un planteamiento estático en la formulación de su concepción inicial, sino que el autor lo ha ido sometiendo a diferentes matizaciones, según este concepto lo haya ido aplicando a los diferentes niveles o esferas de la realidad, que han venido marcando la evolución temática y formal de un teatro aún semioculto.

Hasta 1970 escribe Riaza una serie de piezas que conforman una etapa que, como afirma Ruiz Ramón, «pudiera inscribirse bajo el signo de la desmitificación, por la vía del humor, de las formas dramáticas del teatro occidental contemporáneo ${ }^{3}$. Son los primeros pasos de Riaza por los caminos de la dramaturgia, primeros pasos que consistieron en la crítica y revisión de los modos teatrales que le precedieron y que se desarrollaban, con más o menos vigencia, sobre los escenarios. Se trataba de un análisis de las formas de expresión de la realidad y de los procedimientos de falseamiento y ocultación que éstas implican. Siguiendo de nuevo las palabras de Ruiz Ramón, «en este sentido podemos afirmar que su teatro es uno de los más originales y serios intentos

2 La distinción entre tema genérico, temas concretos y motivos argumentales en el teatro de Luis Riaza a lo largo de estas páginas separa el nivel de la mínima base temática común a toda su producción, del nivel del núcleo de contenido específico de cada pieza y del de las anécdotas que se van sumando hasta constituir la trama argumental. Mientras los últimos cambian necesariamente de un título a otro, sin ningún tipo de relación, los segundos ofrecen una clara línea de evolución y el primero permanece constante a lo largo de todo el ciclo de obras que estamos comentando.

3 Ruis Ramón, Fancisco, Historia del teatro español. Siglo XX, Madrid, Cátedra, 1975, p. 553. 
de poner en cuestión, desde el teatro mismo, la autenticidad y la eficacia de las nuevas formas del teatro ${ }^{4}$. Lo que hace Riaza en estas obras es poner a prueba las dramaturgias vigentes y, sobre su crítica, establecer las bases de su propia y personal poética teatral, cuyos elementos formales básicos fueron delimitándose en esta primera etapa a partir de los elementos formales de las dramaturgias puestas en cuestión.

El tema fundamental de estas piezas, luego rechazadas por el autor como meros ensayos y ejercicios estilísticos, era el teatro en sí y por sí mismo, tema desarrollado de manera general en forma de teatro dentro del teatro, como ocurre en Los círculos ${ }^{5}$, obra en la que el tema fundamental y la forma en que éste se desarrolla coinciden completamente: se trata de la contraposición dialéctica de dos enfoques teatrales diferentes, el naturalista-burgués y el esperpéntico-no-burgués, como el propio autor confirma explícitamente ${ }^{6}$. La preocupación esencial es el diseño y desarrollo de una dramaturgia que soslaye, superándolos, los defectos inherentes a las formas teatrales hasta entonces en vigor. Así, no sólo el teatro burgués es sometido a una dura crítica, sino que lo mismo ocurre también con las corrientes de moda más recientes y de carácter más vanguardista, tan en boga en la década de los sesenta, desde Brecht a Grotowski, desde Artaud hasta el «happening», según más tarde Riaza rememorará en uno de sus prólogos ${ }^{7}$.

A partir de 1970 Riaza parece haber encontrado ya su auténtica y personal voz dramática. En este año escribe una de sus obras más logradas y que, indiscutiblemente, abre un período de madurez dramática, superada ya la etapa de tanteo y preparación. Se trata de El desván de los machos y el sótano de las hembras ${ }^{8}$, en la que la temática del

4 Idem.

5 Los círculos. Inédita. Representada en Madrid (1973) por el Grupo Teatro Aguilar. Gira por Marruecos, en Tetuán, Tánger y Larache, por el Grupo Teatro Apolo de Madrid (1974). En el Festival de Sitges (1975) y en Sevilla fue representada por el grupo Tabanque de esta ciudad.

6 En el texto del programa de mano de la representación de esta obra por el Grupo Teatro Aguilar en Madrid.

7 Riaza, Luis «Prólogo sobre casi todo lo divino y lo humano...», en El desván de los machos y el sótano de las hembras. El palacio de los monos, Madrid, Cátedra, 1978.

8 El desván de los machos y el sótano de las hembras (1970). Publicada en Pipirijaina. Textos, n. ${ }^{\circ} 3,1974$, y en la edición citada en la nota 7 . Representada en el Festival de Sitges de 1970, por el grupo T.E.C.H. de Sevilla; por el grupo Corral de Co- 
teatro como alienación se encarna en una problemática más concreta y delimitada: el enfrentamiento entre el principio del poder y el principio de la libertad, y los mecanismos de que aquél se vale para seguir garantizando su predominio. Lo que en la primera etapa no llegaba a incardinarse más allá de la dimensión puramente teatral, alcanza en las obras de este período una mayor profundización y complejidad, ya que, sin abandonar esa reflexión sobre el teatro hecha desde dentro del propio teatro que caracterizaba sus obras primeras, la dimensión política en la que se mueven las piezas comprendidas entre El desván y EI palacio de los monos ${ }^{9}$, de 1977 , aporta una multiplicación de las valencias semánticas de los elementos que componen la teatralidad riacesca. La concreción no supone en Riaza limitación y univocidad, sino, más allá de su apariencia paradójica, complejidad, provocada por la puesta en juego de nuevos reflejos especulares en la temática de sus piezas. El teatro como paradigma de los mecanismos de alienación es tratado ahora des-

medias de Valladolid (1975); por el Aula de Teatro de la Universidad de Valladolid en dicha ciudad y en gira por Estados Unidos; por el grupo Ditirambo, de Madrid (1978-1979), en diversos puntos de España y en gira por Estados Unidos.

9 En este grupo cabe incluir, además de El desván, las siguientes:

-Representación del Tenorio a cargo del carro de las meretrices ambulantes (1971). Publicada en Riaza, Hormigón y Nieva, Representación... Judith y Holofernes. Teatro furioso, Madrid, Cuadernos para el Diálogo, 1973. No representada.

- Drama de la dama que lava entre las blancas llamas (1974). Constituye la segunda parte de la Nueva Divina Comedia. Fue publicada en Primer Acto, n. ${ }^{\circ} 172$, septiembre de 1974. Representada en Nerja por un grupo de teatro de la localidad.

- Los perros (1976). Comenzada en 1974 con el título provisional de Representación de Don Carlos, de Riaza, en las mazmorras de palacio, posteriormente se denominaría Los huevos de la moscarda, hasta recibir el título definitivo de Los perros, con el que consigue el Premio Lazarillo de Teatro (1980), de Valdepeñas, donde fue representada por un grupo de esta localidad. Publicada en 1986 por la Universidad de Murcia, ed. J. A. Aliaga.

- Retrato de Dama con perrito o Drama de la dama pudriéndose (1976). Publicada en Madrid, Fundamentos, 1976. Representada en Vigo por Teatro Esperpento «La Picota» (1976); en Málaga y Granada por el Grupo de Teatro de Málaga (1976); en Córdoba por el Grupo de Teatro La Garnacha, en las II Jornadas de Teatro, en 1980; en Caracas, en montaje de Armando Gotta (1982).

Elegida por el Centro Dramático Nacional para su representación, se estrena en marzo de 1979 en el Teatro Bellas Artes de Madrid, dirigida por Miguel Narros, obteniendo el premio «El espectador y la crítica» a la mejor obra de autor español estrenada en ese año. A raíz de este estreno, se publica en Madrid, Vox, 1980 , en una versión que presenta variaciones de forma y contenido respecto a la anterior edición.

-El palacio de los monos (1977). Publicada en la edición anteriormente citada. Estrenada en el Festival Internacional de Sitges de 1979 por el grupo «El lebrel blanco» de Pamplona. 
de la perspectiva de su puesta al servicio de unos intereses determinados - los intereses de perpetuación-, de una clase o principio concretos -los del poder-.

A este ciclo de obras ponen punto final Antígona... ;cerda! ${ }^{10} \mathrm{y}$ Revolución de trapo ${ }^{11}$. La primera pone en pie el fracaso definitivo de la constante que en el anterior teatro de Riaza suponía la que podemos denominar «teoría del principio traidor», en torno al papel de los hijos del poder ${ }^{12}$, de quienes debía surgir el principio de su destrucción definitiva, pero que se revelan definitivamente incapaces de una verdadera revolución que vaya más allá de la mera figuración. La segunda supone la puesta en cuestión del propio proceso revolucionario, aun cuando éste surge entre los de abajo, pero capitalizado finalmente por los mismos que antes ejercían el poder, ejemplificando esta distorsión a través de un ejercicio épico-narrativo sobre la manipulación de la revolución francesa por la burguesía.

El cierre de este auténtico ciclo de piezas de subyacente temática política conduce la dramaturgia de Riaza hasta una nueva etapa, en la que el autor ha venido trabajando hasta el momento actual y que se centra con insistencia en el problema de la soledad, provocada por un enajenante sentido de la emulación competitiva que impide una comunicación efectiva entre los miembros de una colectividad, tal como el propio Riaza formula, siguiendo el pensamiento del pensador francés

10 Antígona... icerda! (1980). Publicada en la revista Estreno, vol. VIII, n. ${ }^{\circ} 1$, primavera de 1982, University of Cincinnati. USA. Más tarde, fue recogida en un volumen junto con Mazurka y Epílogo, Madrid, Colección La Avispa, 1983. No representada.

11 Revolución de trapo (1980). Inédita. No representada.

12 En todas las piezas que se agrupan en este ciclo de teatro sobre el poder resulta una constante, hasta el punto de constituir un significativo rasgo definitorio a nivel estructural, la aparición de un personaje que ejerce la función de heredero del poder, de sucesor del actual señor. Mientras en la Representación del Tenorio se trata de un papel intercambiable, en el resto de las obras toma encarnadura dramática en figuras específicas del conjunto de «dramatis personae». Es Ti Prans en EI desván y El palacio de los monos, Señorito en Drama de la dama que lava entre las blancas llamas, Pequeño Rey en Los perros y Artista Adolescente en Retrato de Dama con perrito. En ellos se concentra toda la esperanza por sus juegos de contestación aparentemente revolucionarios, pero de manera inexorable acaban imponiéndoseles los lazos de origen y la fascinación del poder, para consagrarse a unos renovados y confirmados mecanismos de perpetuación. 
René Girard ${ }^{13}$. En este nuevo ciclo se inscriben todos los títulos de su última producción dramática: Mazurka, Medea es un buen chico, Retrato de niño muerto y Epílogo ${ }^{14}$.

Si hubiera que señalar unas razones externas a esta evolución, habría que centrarlas en el progresivo escepticismo del autor ante la posibilidad de cualquier tipo de cambio o alteración en la dinámica social, escepticismo del que no es del todo ajeno el tan traído y llevado desencanto que ha seguido al período de transición post-franquista. No se trata de otro sentimiento que el mismo desencanto que aparece claramente reflejado, en la obra de Riaza, en El palacio de los monos, centrada concretamente en los mecanismos de perpetución del poder por medio de las ceremonias de sucesión, una vez muerto «el Señor», tema reflejo de la situación política real de la España del momento (1977). Ya en esta obra el fracaso de la rebelión de Chica de Botica, el persona-

13 En el encabezamiento de su penúltima obra, Retrato de niño muerto, Riaza hace explícita su deuda con Girard incluyendo un significativo fragmento de este autor:

El sujeto desea el objeto porque el rival mismo lo desea; el deseo es esencialmente mimético; toda mímesis relacionada con el deseo desemboca fatalmente en conflicto; a partir de un cierto grado de frenesí conflictivo la polarización mimética se proyecta hacia una víctima única. Después de haberse saciado sobre esta víctima, la violencia forzosamente se interrumpe, el silencio sucede al frenesí...

René Girard

El pensamiento del filósofo francés se desarrolla en obras como La violencia y lo sagrado, Barcelona, Anagrama, 1983, y Literatura, mímesis y antropología, Barcelona, Cedisa, 1984. La aplicación de sus teorías al ámbito específico de la crítica y el análisis de la literatura y el teatro la lleva a cabo en lengua española Cesáreo Bandera en su estudio Mímesis conflictiva, con prólogo del propio Girard, Madrid, Gredos, 1974.

14 Salvo la última pieza, un monólogo de características muy específicas, el resto de las obras citadas presentan una semejanza notable y una enorme coherencia temática. Mazurka (1980). Publicada en el volumen citado de Colección La Avispa de Madrid. Programada por Televisión Española para la serie «Teatro breve», dedicada a autores españoles contemporáneos.

Medea es un buen chico (1980). Publicada en Pipirijaina, n. ${ }^{\circ} 18$, enero-febrero de 1981. Representada en enero de 1985 en una coproducción entre el Círculo de Bellas Artes de Madrid y en Centro Nacional de Nuevas Tendencias Escénicas, dirigida por Luis Vera.

Retrato de niño muerto (1982), concebida con el título de Las obras, recibió para su realización una ayuda a la creación teatral concedida en noviembre de 1981 por la Dirección General de Música y Teatro. Más tarde se denominó provisionalmente El diosecito de la casa y recibió el título definitivo al final de su redacción. Estrenada en febrero de 1984 en la Universidad de Málaga por el grupo Teatro de las Musarañas, de Madrid, dirigido por Luis Vera.

Epílogo (1983). Publicada en el citado volumen de Colección La Avispa. No representada. 
je que encarna a las víctimas de la dominación, conduce a un sentimiento de soledad que traslada la temática riacesca a una dimensión de carácter más individual, tal como el intento de Chica de Botica no va más allá del plano puramente personal por no encontrar quien lo secunde. La inviabilidad del proyecto de acción colectiva deja paso a la nueva perspectiva del último teatro de Riaza, en la que el eje central se ha desplazado a las respuestas individuales y su asimilación ante las presiones de un sistema social que no ha visto alterada su esencia más íntima y definitiva.

De cualquier manera, bien tratado en forma especifica, bien a través de su contemplación en su esfera política o puramente humana individual, el tema del teatro, de la puesta en evidencia de sus posibilidades de manipulación y de los efectos con ella conseguidos, no abandona en ningún momento la obra de Riaza, que se genera a sí misma como una reflexión sobre el teatro a partir de sí mismo. Esta preocupación constituye lo que podríamos denominar un «metatema» ${ }^{15}$, en el sentido de que se localiza más allá, a un nivel más profundo, de la inmediatez temática concreta de cada obra. Para Riaza, este «metatema» es el único posible, el único válido para una verdadera literatura:

Sólo se hace literatura sobre literatura, teatro sobre teatro ${ }^{16}$,

No se hace literatura sobre la realidad (que hemos quedado que no existe) sino literatura sobre literatura ${ }^{17}$.

Como la mayor parte de las grandes creaciones poéticas, su teatro no se construye directamente sobre el universo de lo real, sino que entre uno y otro interpone el autor formas de expresión de esa misma realidad anteriormente elaboradas, usándolas, más que como meros recursos formales, como auténtico principio estructurante en la creación de su teatro y clave de su poética dramática. Es más, como el tema esencial sobre el que gira toda su obra.

Esa pre-visión de la realidad en forma de dramaturgias y estéticas teatrales precedentes, que Riaza introduce, como si de un prisma se tratase, entre el mundo objetivo y su propia visión personal del mismo,

15 Seguimos como modelo de la acuñación y del sentido de este término los correspondientes a los conceptos de metafísica o metahistoria.

16 Riaza, Luis, El desván, ed. cit., p. 110.

17 Riaza, Luis, Medea es un buen chico, ed. cit., p. 10. 
es lo que contribuye de manera decisiva a la referida multiplicación de niveles significativos que se incluyen unos dentro de otros como el juego de las muñecas rusas, de teatro dentro del teatro dentro del teatro dentro del teatro..., y así indefinidamente. En ello radica la base sobre la que se asienta toda su estética teatral, su visión de la elaboración de su propia dramaturgia. Sin embargo, este recurso o, más exactamente, este principio estructural, no se queda en un mero nivel formal. Hay algo más que el puro juego teatral confesado por el autor. Como Ortega y Gasset afirmaba de Kant, Riaza retiene su mirada no para ver el paisaje, sino para ver el cristal a través del cual podemos contemplar ese paisaje. Esto es, el análisis del teatro de Luis Riaza no se centra tanto en la realidad misma, como en los mecanismos que encauzan, filtran y deforman su percepción, es decir, el prisma al que antes nos referíamos y que Riaza introduce en su teatro como estética deformante, como un verdadero espejo del callejón del Gato. Lo que diferencia a Riaza de Valle-Inclán es que aquél introduce la visión deformante no como un medio, sino como un fin en sí mismo. Valle pasea a sus personajes delante de sus esperpénticos espejos para comprobar la nueva imagen que éstos reflejan. Convirtiéndolo en un proceso de indagación epistemológica, Riaza, por el contrario, lo hace para analizar y mostrar los mecanismos de deformación a que estos espejos someten la realidad.

Ante una circunstancia real opresiva y cerrada, tal como Riaza nos presenta en los espacios escénicos de sus obras - castillos, palacios, balnearios... siempre herméticamente cerrados al exterior y en estado avanzado de descomposición-, ante esa caverna platónica donde sólo sombras y figuración tienen cabida y son objetos de percepción, sólo signos sustituidores de la realidad y no la realidad misma, el teatro de Riaza se levanta sobre el compromiso del descubrimiento y la denuncia de los procedimientos que mantienen al hombre en ese estado de enajenación, ayuno de una realidad escamoteada por determinados intereses: «Se ha pretendido - afirma Riaza - un desmontaje de los mecanismos de fascinación» ${ }^{18}$. Estos mecanismos son, según él, los de simulación y sustitución que definen el teatro, el arte basado en el engaño y el fingimiento, el arte que acaba ante la más mínima irrupción de realidad, ya que se asienta únicamente sobre las convenciones delimitadas por el espacio escénico, que, a su vez, no es más que una mera convención del espacio de la realidad. Pero en este caso el término «teatro» sólo es una

Riaza, Luis, Retrato de Dama con perrito, ed. cit., p. 18. 
sinécdoque, pues se le da el nombre de una sola parte a todo el conjunto, «llamado teatro con notoria exageración — según hace constar el propio autor-, puesto que tal vocablo sólo cubre una parte ínfima, desdeñada por anticuada, de la total manipulación de las luces celestiales» ${ }^{19}$. El teatro se convierte así en paradigma de una serie de formas, desde el rito y la ceremonia hasta cualquier otra pauta de comportamiento sin una relación directa ni inmediata con la realidad, susceptibles de una manipulación que las despoje de sus valores originales, para dotarlas de unas nuevas significaciones, generalmente opuestas a las primeras, que puedan garantizar la alienación y, en consecuencia, el dominio sobre los individuos a los que de alguna manera, por violencia o fascinación, se les imponen estos comportamientos.

El encubrimiento de la realidad encuentra, pues, en el teatro su mejor, aunque no único, ejemplo. Sin embargo, Riaza utiliza el teatro precisamente con la función opuesta, la de convertirlo en un instrumento de descubrimiento de la realidad, a través de un proceso de puesta en evidencia de los mecanismos que impedían el contacto directo con ella. Con esta finalidad surgió en sus inicios el teatro, ceremonia religiosa, que re-liga, que une directamente con la divinidad, la manifestación más profunda y verdadera de la realidad. De ahí la propuesta que en cierta manera formula Riaza de una vuelta a esa significación primigenia del teatro, a su valencia religiosa, ya que, según expresa en su propia reflexión sobre este tema:

En medio de la desacralización del cagado mundo todavía nos queda la esperancilla de poder frecuentar una misa en la que el primer actor haga de sacerdote-verdugo y la primera actriz de sangre del cordero divino [...] Porque, a lo mejor/peor, el teatro se ha quedado en eso, en misa [...], en refugio de la poca religiosidad extraeclesial - también llamada magia- que por el mundo va quedando ${ }^{20}$.

La propuesta de este tipo de teatro lleva aparejada de modo inevitable el rechazo de todas aquellas formas de teatralidad que invierten su naturaleza genuina y, en lugar de descubrir, encubren la realidad:

Forma de teatro breve, teatro documento, teatro telediario, teatro informe semanal, teatro estudio, teatro noticias de última hora en la caverna y teatro-popular-gran-relato-de-cada-noche-dánoslo-hoy ${ }^{21}$.

19 Idem.

20 Riaza, Luis, Medea es un buen chico, ed. cit., p. 8.

21 Idem. 
La televisión, como relevo perfeccionado de las anteriores formas del teatro burgués, un teatro de confirmación de un «status» por reducción de la realidad. La dramaturgia burguesa encarna para Riaza los aspectos más negativos del hecho teatral. Con su estética de la apariencia, del «como si», extrema y deforma el mecanismo de simulación sobre el que se levanta el teatro, con lo que le otorga a éste el sentido peyorativo con que, en ocasiones, se connota este término, convirtiéndolo en sinónimo de hipocresía, de falsedad.

La labor desenmascaradora del teatro de Riaza no acaba en la denuncia, pues su autor es consciente de que la aceptación acrítica de los modelos que vienen a sustituir a las dramaturgias burguesas incurriría en el mismo peligro que se viene a soslayar, el de caer en una visión reductora de la realidad que conduzca a un nuevo tipo de alienación, aunque sea éste de signo opuesto al anterior. De esta forma, lo mismo que en el «Prólogo sobre casi todo lo divino (y lo humano)...» que antepone a su edición de $E l$ desván de los machos y el sótano de las hembras y El palacio de los monos, a la crítica implacable al teatro burgués sigue la de las formas del pretendido teatro popular; Los círculos, pieza en la que estas últimas formas se consideraban aún válidas, deja paso en la trayectoria creativa de Riaza a la Representación del Tenorio a cargo del carro de las meretrices ambulantes y la fórmula dramática que ella aporta, en la que la crítica del teatro como instrumento de alienación y represión en manos de las clases dirigentes se concreta en un determinado momento en la parodia de las formas teatrales de vanguardia, las que vienen a ofrecerse como sustitución de la dramaturgia burguesa:

MADAM (a Negro $1 .^{\circ}$ ): Espectáculo A. Ejercicio bertolbrechtiano, lógicodidáctico, épico-narrativo y pragmático-concienciativo ${ }^{23}$.

MADAM: [...] Espectáculo B. Ejercicio antoninoartodiano, mágicodesinhibitorio, público-agresivo, escénico-sangriento y pajarito-sacrificativo ${ }^{24}$.

MADAM: [...] Espectáculo C. Ejercicio antoninobertoldoartobrechtianoyjercigrotosquiano, místico-privativo, somático-liberatorio, recobraprimitivo, olfativo, auditivo, pero no palpático» ${ }^{25}$.

22 En Riaza, Luis, El desván, ed. cit.

23 Riaza, Luis, Representación del Tenorio, ed. cit., p. 76.

24 Idem, p. 83.

25 Idem, p. 93. 
Como se puede apreciar, de esta irónica parodia no se escapa ni la propia propuesta riacesca, especie de síntesis superadora de Brecht y de Artaud y un intento de recuperar el primitivo valor religioso del teatro, intento coincidente con el que en Polonia intentaba llevar a cabo Jerzy Grotowski y su «teatro pobre» ${ }^{26}$. La propuesta teatral que formula Riaza es la de un teatro de ceremonia, pero, a la vez y de manera paradójica, un teatro de ataque a la artificialidad de la ceremonia. La base de todo su teatro es el rechazo de la fascinación que éste puede ejercer sobre el espectador, como único camino para evitar su enajenación, lo que la dramaturgia brechtiana intentó conseguir por medio del distanciamiento épico y el «efecto $\mathrm{V}$ », pero desarrollando al mismo tiempo un didactismo escrupulosamente evitado por el teatro riacesco. De otro lado, este rechazo de la fascinación no se lleva a cabo con la huida sistemática de cualquier elemento que suponga una tentación de este tipo, sino, por el contrario, siguiendo el camino opuesto, es decir, sumergiéndose, y sumergiendo consigo al espectador, en esa fascinación ejercida por los mecanismos teatrales de sustitución de la realidad, adentrándose en ellos y poniendo al descubierto por medio de elementos de la propia ceremonia lo que ésta tiene de falsedad. La violenta sacudida que el descubrimiento de tales procedimientos provoca en el espectador es lo que arrastra inevitablemente el rechazo de los mismos, pero no obedeciendo a una consigna lanzada desde el escenario, sino adoptando una postura activa, que también conecta por su parte con la naturaleza original del teatro y la colectiva participación en la celebración ceremonial.

El carácter de la ceremonia, del rito es el de la rememoración y repetición de un mito o hecho primordial. Es decir, se trata de revivir, de dar nueva vida, a una visión originaria de la realidad, a una imagen de la misma captada en su esencia más pura, sin ningún tipo de elemento de deformación. Pero la ceremonia no se compone exclusivamente del elemento mítico, sino que en ella también entra a formar parte de manera esencial el elemento de repetición, que, por un olvido y degradación de su origen primitivo, puede derivar, al fosilizarse, hacia un desvirtuamiento de su significado inicial, desvirtuamiento que se convierte en el camino más seguro para toda manipulación a la que se desee someter la ceremonia, reducida ya a un conjunto de acciones despojadas de todo significado y dispuestas a adquirir uno nuevo. Ésta es su

Véase Grotowski, Jerzy, Teatro laboratorio, Barcelona, Tusquets, 1970. 
paradoja esencial y en ella se basa la paradoja del teatro riacesco: la ceremonia, el contacto más directo con la auténtica realidad, con la realidad primigenia, se convierte en el instrumento más útil en el proceso de enajenación a que se somete al individuo receptor, cuyo paradigma es, evidentemente, el espectador teatral. Riaza utiliza el teatro, y precisamente el teatro de la ceremonia, como medio de denuncia y anulación de la efectividad que los propios mecanismos de alienación tienen sobre el individuo receptor.

¿Y por qué precisamente el teatro? ¿Por qué usar el propio objeto como instrumento de su puesta en cuestión? Porque, si bien el teatro ha sido uno de los más utilizados y efectivos medios de deformación y control ideológico, hasta el punto de convertirse en paradigma denominador de estos medios, al mismo tiempo se trata de la relación emisorreceptor que ofrece más virtualidades de desalienación, la que permite un más lúcido autoanálisis; en una palabra, la que es más susceptible de convertirse en tema -o «metatema»- de sí misma. Ante esta ambivalencia del teatro actúa la dicotomía fundamental de la dramaturgia de Riaza, que se mueve entre esos dos extremos de fascinación y repulsión, de atracción y rechazo, de amor y odio a la vez, sentidos hacia el teatro, que, en su pugna dialéctica se resuelve finalmente del lado positivo, de atracción, ya que, de otro modo, su teatro no tendría existencia real, habría derivado hasta el silencio, tal como ha ocurrido con el último Beckett.

Del lado de la repulsión actúa la consciencia de la fácil manipulación del teatro como sustitutivo de la realidad. «Veo que el teatro es un ejemplo concreto de dar signo por realidad, gato por liebre, para que tal signo sirva de consuelo...», afirma Riaza en entrevista con Ángel García Pintado, para continuar más adelante: «El teatro, como género, ha sido a través de los tiempos un consolador, un ocultador de la verdadera realidad. Hay que tener en cuentä que ha sido la televisión del siglo XVI. Se ha servido siempre como sucedáneo de la realidad ${ }^{27}$.

Del otro lado, del de la atracción que le impulsa hacia el teatro, se encuentran las características que antes señalábamos y que lo diferencia de otras formas comunicativas que, como la televisión, la denos-

27 García Pintado, Angel, «El Dante Riaza: entre el más allá y el más acá», entrevista con Luis Riaza, en Primer Acto, n. ${ }^{\circ} 172$, septiembre de 1974, p. 10. 
tada «circepantalla», no ofrecen para el espectador posibilidad alguna de sustraerse a su influjo alienador:

Hay quien dice

(ese quien era/soy yo $[. .$.

que existe una diferencia de grado entre convertirse en cerdo delante de una circepantalla o delante de un escenario.

Es decir, que la sustitución de la vida de que se viene tratando es diferente si uno se queda con la pasividad y el buche abierto para que arrojen a uno masticadillo de realidad desde el culo de la maga, que si lo hace embutacado frente a unos entes de hueso - y algo de carne - llamados cómicos, los cuales también tienen culo y lo menean - aunque en tres dimensiones- dentro de la más estricta liturgia de la expresión corporal. Cómicos que, aunque de lejos, huelen ${ }^{28}$.

La tercera dimensión que ofrece el teatro como ventaja sobre otros mecanismos de reducción de la realidad a los límites de un discurso, como la plana pantalla de televisión, es la que dota a este medio de su profundidad. Gracias a ella es posible la multiplicación de sus niveles de significación, entre los que cabe, por ejemplo, el de la puesta en cuestión de sí mismo como género y de la falsedad esencial que lo sustenta, con lo que se abre una puerta de entrada a una dimensión de realidad, ese olor de los cómicos de que habla Riaza. Este mecanismo es el que permite al espectador percibir la naturaleza convencional, no real, de lo que ocurre ante su vista, percepción que es un primer paso para salir del engaño, para escapar de la enajenación. Los pasos siguientes corresponden ya al propio receptor de la obra de Riaza, que nunca encontrará en su teatro ningún rastro de didactismo ni un discurso elaborado para facilitar su aceptación pasiva. Por el contrario, tras el desmontaje del sistema de la sustitución, las ceremonias riacescas requieren del espectador su más activa participación, un aporte de cocreatividad con el que pueda dotarse de sentido a la labor de desbrozamiento que constituye el núcleo de todas estas piezas. En la búsqueda continua de dejar al espectador enfrentado con la realidad queda abierto un nuevo espacio libre de la figuración que el propio teatro ha contribuido a crear. Con ello, Riaza cierra el círculo en el que se mueve su teatro y en el que descubre su esencia más íntima de desenmascaramiento del propio teatro. Despojado de todo disfraz, el teatro riacesco no sólo cumple con

Riaza, Luis, Medea es un buen chico, ed. cit., pp. 6-7. Se trata del apartado significativamente titulado «De los sótanos del castillo», en un prólogo en el que Riaza ofrece expresivas pruebas de su preocupación por la problemática que hemos venido señalando como metatema de su teatro. 
su finalidad de descubrimiento de la realidad, sino que, y he aquí su fundamental importancia, recobra con ello su naturaleza primera, la que gozó el teatro primigenio antes de ser desvirtuado en el proceso cultural y civilizador.

De esta manera, un teatro que rechaza el fácil expediente de ejercer su fascinación sobre el espectador y demanda de éste una participación efectiva en el proceso de creación, a través de esa puesta en cuestión de sí mismo como objeto que caracteriza la teatralidad de Riaza, es el teatro que alcanza su verdadera categoría dentro de la jerarquia de las artes. En ella ostenta, según este autor, un lugar de privilegio, precisamente por su capacidad comunicativa y el alto grado de cocreatividad que demanda del espectador. Éste ha de sustituir su tradicional pasividad por la reelaboración creativa de su propia obra a partir de la complejidad y multiplicidad de niveles de interpretación que se le ofrecen como propuesta a partir del texto dramático. La participación del receptor exigida por la dramaturgia riacesca revierte sobre él mismo a la manera de un efecto catártico, para poner fin a una situación de enajenamiento producida por la fascinación ante los mecanismos teatrales. La intención con que se plantea esta dramaturgia no es en absoluto ajena a esta suerte de «catarsis» que, por seguir hablando en los términos de la magia que el autor requiere para el teatro, actúa como un conjuro o, mejor dicho, como un contra-conjuro frente a la ocultación y el escamoteo de la realidad: al poner al descubierto los mecanismos de fascinación que utiliza el teatro para su sustentación, al señalarlos, al «nombrarlos», éstos pierden su poder sobre el espectador, produciéndose ese «desmontaje» que Riaza confiesa pretender con su teatro ${ }^{29}$.

La consecuencia inmediata de esta compleja serie de operaciones a que Riaza somete su dramaturgia es la desaparición del prisma a que hacíamos referencia páginas atrás, situado entre la realidad y el sujeto de la percepción para producir en ella una deformación en un sentido determinado. Por este camino, lo que sigue es la aparición de la realidad sin ninguna forma de ocultación o simulación. La enajenación del sujeto desaparece y éste recupera su libertad y su posibilidad de contacto y percepción directa del universo que le rodea. Como una paradoja más dentro del teatro riacesco, ello supone la desaparición del propio teatro y de cualquier otro de los mecanismos sustitutorios que surgen 
cuando el hombre, a través de un proceso de alienación, pierde su capacidad original de contacto y comunicación con la naturaleza esencial, con la divinidad, cuando del grupo de las bacantes se destacan unas figuras que actúan como vicarios, como intermediarios - como actores, en definitiva-, para otras figuras que se mantienen en el plano pasivo de espectadores. La solución de la aparente contradicción de un teatro que representa la muerte del teatro se halla sin ninguna dificultad cuando invertimos este planteamiento y descubrimos cómo en la obra de Riaza la muerte del teatro se convierte en el fermento creativo de un nuevo teatro. A un nivel mucho más evidente, la demolición del teatro se convierte en la principal fuente argumental de la dramaturgia riacesca y de cada una de sus piezas en particular, hasta el punto de permitirnos la referencia a su producción como un «metateatro», entendiendo este concepto de manera paralela al de «metalenguaje», que al mismo tiempo nos sirva de base para la configuración del término. Separándonos de Lionel $\mathrm{Abel}^{30}$ en la formulación del concepto al que resulta aplicable semejante término, entendemos por metateatro aquel que se tiene a sí mismo como objeto de reflexión, convirtiendo su gramática específica en la base de sus argumentos, según el modelo de la función metalingüística del lenguaje que delimitara Roman Jakobson y que definiera como el lenguaje que se toma a sí mismo como referente ${ }^{31}$.

En este terreno, la obra dramática de Luis Riaza no sólo puede ser considerada como una forma de metateatro, sino también como un auténtico contra-teatro. No nos referimos con ello al sentido que Francisco Nieva le da a esta misma denominación cuando escribe en un prólogo sobre el teatro de este autor. Para el creador del «teatro furioso» el valor de este término referido a la producción de Riaza se concreta en la manifestación de «una voluntad de escribir contra lo habitual en la escena» ${ }^{32}$. La certeza de esta afirmación sobre la inhabitualidad y la voluntad de ruptura que Riaza introduce en relación con el panorama teatral español resulta a todas luces evidente, pero, desde la perspectiva que hemos venido trazando, se mantiene a un nivel un tanto epidérmi-

30 Véase Abel, Lionel, Metatheatre, A new view of Dramatic Form, New York, Hill and Wang, 1969.

31 Véase Jakobson, Roman, Lingüística y poética, Madrid, Cátedra, 1983.

32 Nieva, Francisco, «Luis Riaza o la subjetividad heroica», introducción a Retrato de Dama con perrito, ed. cit., p. 13. 
co, pues Riaza no sólo escribe contra lo habitual en la escena española, sino contra la propia esencia del género teatral, que es la figuración.

Sin embargo, como ya queda apuntado, Riaza convierte el acta de defunción del teatro en un nuevo soplo de vida para éste, y a esa tendencia a la disgregación se opone de manera efectiva la atracción que el autor siente por el propio objeto hacia cuya anulación dirige su obra. Como el mismo Riaza define, el suyo es un antiteatro que se regodea en su propia naturaleza teatral, teatro que es un metateatro, pues se constituye como una reflexión sobre sí mismo, buscando su propia destrucción, pero entreteniéndose en el fango de su fascinación, de la ineludible atracción inconsciente por lo que en el nivel de la consciencia se condena, por esa teatralidad que nuestro autor identifica con traición ${ }^{33}$. A pesar de ello, el teatro de Riaza se sumerge en ella, aunque solamente sea «con el único fin de destruirla, de erostratizarla», por exponerlo con sus propias palabras ${ }^{34}$; aunque sea contra la confesada voluntad del autor, «puesto que se trata de un teatro - continúa Riaza- que no se quiere tal, de un teatro que se niega a sí mismo, que socava sus propios cimientos, un teatro de una teatralidad malgré lui, una teatralidad malquerídica, un teatro rezumando incertidumbre, un teatro que se pregunta siempre, con retorcimiento total de tripas, quién es él» ${ }^{35}$, pero en el que se asienta firmemente la dramaturgia riacesca en virtud de esa oposición dialéctica, de esa aparente paradoja que la impregna por completo.

33 Riaza, Luis, El desván, ed. cit., p. 109.

34 Idem.

35 Idem. 